\section{AB0052 PROGRESSIVE SYMMETRIC ARTHRITIS AS AN EARLY MANIFESTATION OF ADENO CARCINOMA OF THE LUNG}

${ }^{1} \mathrm{M}$ Welcker, ${ }^{1} \mathrm{H}$ Hobert, ${ }^{2} \mathrm{~K}$ Welcker, ${ }^{1} \mathrm{D}$ Kaufmann, ${ }^{1} \mathrm{H}$ Franck. ${ }^{1}$ Centre of Rheumatology, Waldburg Zeil Kliniken, Oberammergau; ${ }^{2}$ Clinic of Lung Disease, Asklepios, Gauting, Germany

\subsection{6/annrheumdis-2001.1017}

Background In may 1999 a 57 year old woman presented progressive symmetric arthritis of the hand, fingers and forefoot over a period of more than 6 weeks. Laboratory testing revealed an elevated sedimentation rate, increased $\mathrm{C}$ reactive protein levels and secondary signs of inflammation (elevated ferritine, alpha-2-fraction in the serum electrophoreses, etc.). The radiograph showed juxtaarticular osteoporosis without further signs of joint destruction. The x-ray of the chest was normal (performed for reasons of nicotin consumption over years and the intention of methotrexate therapy) without signs of malignancy.

Initially the patient was treated as an outpatient. Although the initiated DMARD-therapy with methotrexate was well tolerated at a dose of $15 \mathrm{mg}$ orally per week she was finally admitted to the hospital in December 1999 for reasons of further deteriorating of the arthritis and the general feeling.

Symmetrical arthritis and elevated sedimentation rate revealed continuous inflammation. An x-ray control of the hand and feet showed a fine periostal hyperostosis suspective for "osteoarthropathy hypertrophiante pneumonique Pierre Marie Bamberger". The x-ray of the chest was suspective for a malignant process of the lung, a diagnose that was confirmed by computer tomography. Histological examination revealed an adeno carcinoma of the lung. Consecutive palliative chemotherapy led to improvement of arthritis.

Objectives ./.

Methods ./.

Results ./.

Conclusion This is a case of malignant lung disease with the rare initial symptom of symmetric progressive arthritis and periostal hyperostosis, improving after chemotherapy.

\section{AB0053 RHEUMATOID LUNG DISEASE AS A PRESENTING FEATURE OF RHEUMATOID ARTHRITIS}

${ }^{1} \mathrm{P}$ Borman, ${ }^{1} \mathrm{G} A \mathrm{Ak}^{2} \mathrm{~N}$ Barca, ${ }^{1} \mathrm{H}$ Bodur. ${ }^{1}$ Department of Physical Medicine and Rehabilitation; ${ }^{2}$ Radiology, Numune Education and Research Hospital, Ankara, Turkey

10.1136/annrheumdis-2001.1018

Background Pulmonary involvement is a common extraarticular feature of rheumatoid arthritis (RA) but early symptomatic manifestations of RA are uncommon. We present 2 male RA patients with all characteristic features of pulmonary involvement which preceded the articular symptoms and occurred concurrently.

Case1; A 32-year-old male presented with severe pulmonary involvement due to the rheumatoid nodules, pleurisy, atelectasis, interstitial fibrosis which preceded the articular symptoms. Case 2; A 54-year-old male presented with articular manifestations of RA associated with typical pulmonary findings of rheumatoid lung including paranchimal nodules, pleurisy, interstitial fibrosis and honey-comb appearance simultaneously. In both cases the diagnosis were made after exclusion of other causes of pulmonary disease and depending on the findings of pleural biopsy.

In conclusion the onset of RA with severe typical pulmonary findings are not uncommon and physicians must be aware of this extraarticular finding as a presenting feature of RA.
Objectives

Methods

Results

Conclusion

\section{AB0054 THE ROLE OF THE GUT IN REACTIVE ARTHRITIS}

${ }^{1} \mathrm{E}$ Rezus, ${ }^{1} \mathrm{C}$ Chiriac, ${ }^{2} \mathrm{C}$ Rezus, ${ }^{1} \mathrm{R}$ Chiriac. 'University of Medicine and Pharmacy, Rehabilitation Hospital, Department of Rheumatology, Romania; ${ }^{2}$ University of Medicine and Pharmacy, III; Rd Medical Clinic, lasi, Romania

\subsection{6/annrheumdis-2001.1019}

\section{Background}

Objectives The present study propose to observe the relation between the gut and synovitis in enteretic and urogenic reactive arthritis (ReA).

Methods Forty patients with ReA were included in the study according to Amor criteria: 25 patients with enteric entrance gate and 15 patients with urogenic entrance gate. We had in view the inflammatory syndrome, immune syndrome, identification of the infectious ?trigger? (serology for Yersinia, Shigella, Salmonella, Chlamydia). Concomitant were effected rectosigmoidoscopy with biopsy and synovial biopsy.

Results $75 \%$ of patients had inflammatory intestinal lesions like active and chronic colitis and proctitis. We found a correlation between persistance of the intestinal inflammation and the evolution of the inflammatory process in the joint. The immunglobulins A were increased at $50 \%$ of patients which prove the existence of a persistent antigenic stimulation to the bowel level. At 10 patients with urogenic ReA we observed a remarkable aspect: the presence of subclinical inflammatory lesions to the intestinal mucosa.

Conclusion The rectosigmoidoscopy with biopsy back the role of the bowel in ReA, even at the patients which have not obvious clinical gastrointestinal manifestations.

\section{OP0007 MRI OF THE WRIST AND FINGER JOINTS IN INFLAMMATORY JOINT DISEASES AT ONE YEAR INTERVAL. MRI FEATURES TO PREDICT BONE EROSIONS}

${ }^{1}$ A Savnik, ${ }^{2} \mathrm{H}$ Malmskov, ${ }^{3} \mathrm{HS}$ Thomsen, ${ }^{1} \mathrm{LB}$ Graff, ${ }^{4} \mathrm{H}$ Nielsen, ${ }^{1} \mathrm{H}$ Bliddal. ${ }^{1}$ Parker Institute; ${ }^{2}$ Rheumatology, Frederiksberg University Hospital of Copenhagen, Frederiksberg; ${ }^{3}$ Radiology, ${ }^{4}$ Rheumatology, Herlev University Hospital of Copenhagen, Herlev, Denmark

10.1136/annrheumdis-2001.1020

Background Magnetic resonance imaging (MRI) has important applications in inflammatory joint diseases since it allows a direct visualisation of both bony and soft tissue. The wrist and finger joints are first affected in rheumatoid arthritis and of prime interest in predictive studies. Bone oedema is important MRI feature in inflammatory joint diseases and it has been suggested to be a forerunner of bone erosion.

Objectives To compare the ability of the outlined synovial volumes before and after Gadodiamide injection, presence of bone marrow oedema, bone erosions and enhancement after Gadodiamide injection to predict progressions in bone erosions after 1 year follow up in patients with different types of inflammatory joint diseases.

Methods 84 patients underwent MRI, laboratory and clinical examination at baseline and 1 year later. MRI of the wrist and finger joints was performed in 22 patients with rheumatoid arthritis less than 3 years (group 1), 18 patients with 